\title{
Research
}

\section{Safety and efficacy of rectal compared with intramuscular quinine for the early treatment of moderately severe malaria in children: randomised clinical trial}

Hubert Barennes, Tatiana Balima-Koussoubé, Nicolas Nagot, Jean-Christophe Charpentier, Eric Pussard

\begin{abstract}
Objective To compare the safety and efficacy of quinine given by the rectal route with quinine given by the intramuscular route in children with moderately severe Plasmodium falciparum malaria.

Design Randomised, open, clinical trial.

Setting Health centre in Burkina Faso.

Participants 898 children with moderately severe $P$ falciparum malaria who were unable to take oral treatment.

Intervention Rectal quinine $(20 \mathrm{mg} / \mathrm{kg}$ diluted to $30 \mathrm{mg} / \mathrm{ml}$ in water solution) or intramuscular quinine $(12.5 \mathrm{mg} / \mathrm{kg})$ every 12 hours until oral quinine could be taken.

Main outcome measures Primary safety outcome was the presence of blood in stools and secondary safety outcome was diarrhoea. Primary efficacy outcome was early treatment failure and secondary efficacy outcomes were late clinical and parasitological failures, fever clearance time, and time to oral intake.

Results Blood in stools and diarrhoea were more common in children given quinine by the rectal route than by the intramuscular route (blood in stools: $5 \% v 1 \%$, absolute difference $3.9 \%, 95 \%$ confidence interval $1.8 \%$ to $6.1 \%$; diarrhoea: $5 \%$ v 1\%, $3.5 \%, 1.3 \%$ to $5.7 \%$ ). On anoscopy, inflammatory lesions $(9 / 248,3 \%)$ were associated with bloody striations in stools. Side effects of rectal quinine were rare and transitory. Local pain (90\%), inflammation (79\%), and transient impairment of mobility $(15 \%)$ were observed with intramuscular quinine. Early treatment failure was higher in the rectal group $(6 \%$ v 3\%, absolute difference 3.0\%, 95\% confidence interval $0.2 \%$ to $5.9 \%$ ). All except two children in each group had negative blood slide results at day 5 . Fever recurrence at day 7 was higher in the intramuscular group (37/375 v 18/395, absolute difference $5.3 \%, 1.6 \%$ to $8.9 \%)$. Other efficacy outcomes (late clinical failure, late parasitological failure, fever clearance time, time to starting oral intake and rate of deterioration to severe malaria) did not differ.

Conclusion Quinine given by the rectal route has an acceptable safety profile and could be used in the early management of moderately severe malaria in children in sub-Saharan Africa, halting progression to severe disease.
\end{abstract}

\section{Introduction}

Most of the 1-2 million deaths from malaria each year, primarily of African children aged under 5 years, occur at home or at the first level of health care, ${ }^{1}$ when intravenous infusion of quinine is often unsuitable. If oral treatment is not possible, quinine is usually given by the intramuscular route, although often unsafely. ${ }^{2}$ The rectal route, a non-invasive and practical choice, is an alternative means of treating the early stages of severe malaria. ${ }^{3}$ Preliminary studies support the use of rectal quinine. ${ }^{4-7}$ We have shown similar concentration-time profiles of quinine in blood with rectal quinine (20 $\mathrm{mg} / \mathrm{kg}$ of quinine base), intramuscular quinine $(12 \mathrm{mg} / \mathrm{kg})$, and intravenous infusion of quinine $(8$ $\mathrm{mg} / \mathrm{kg}){ }^{8}$ Information on the safety of rectal quinine is limited and larger trials are required. We compared the safety and efficacy of rectal quinine compared with intramuscular quinine in children with moderately severe malaria.

\section{Methods}

Our study was carried out in Hambdallaye Health Centre, BoboDioulasso, Burkina Faso, from September 2001 to December 2002. In this malaria endemic area, isolates are fully sensitive to quinine. ${ }^{9}$ Malaria accounts for $20 \%$ of deaths in children and $28 \%$ of outpatient visits by children. ${ }^{10}$

We included children and young people aged 1 to 15 years with Plasmodium falciparum malaria (axillary temperature $\geq 37.5^{\circ} \mathrm{C}$ and $>1000 \mu \mathrm{l}$ of asexual parasites in blood) who were unable to take oral treatment owing to repeated vomiting, postictal state, general weakness, or moderate stupor. Parents or guardians gave informed written consent. We excluded children with a history of diarrhoea, current anal disease, or those who had received a traditional enema in the preceding week.

On enrolment we carried out a complete medical history and physical examination. Children were followed up twice daily for the first three days and then on days 5 and 7 . Further examination and treatment were available when necessary. We made home visits for missed appointments. During the second year of the study, we added an examination on day 14 (335 children) to look for delayed side effects.

The children were screened for eligibility criteria by a nurse at the health centre. A blood test for parasites was carried out by the study microscopist. If a child was eligible, he or she was sent to the doctor who then sought the consent of the primary caregiver. Treatment was allocated according to a randomisation scheme generated by an independent epidemiologist using EpiInfo version 6.0. The allocation was kept sealed in an envelope until the patient was eligible and consent had been obtained.

\section{Drug administration}

For both the rectal and intramuscular routes we used the intravenous form of quinine gluconate with a $\mathrm{pH}$ of 4.5 (Quinimax, 
containing $96 \%$ quinine, $2.5 \%$ quinidine, and $0.67 \%$ cinchonin and cinchonidin; Sanofi-Synthelabo, Gentilly, France), previously shown to have a similar pharmacokinetic profile to bichlorhydrate quinine. ${ }^{11}$ The intramuscular dose $(12.5 \mathrm{mg} / \mathrm{kg}$ of quinine base) was administered in the gluteal muscle. The rectal dose (20 $\mathrm{mg} / \mathrm{kg}$ of quinine base) was prepared by dilution of quinine gluconate in water to obtain a $30 \mathrm{mg} / \mathrm{ml}$ solution. The solution was administered through a $10 \mathrm{ml}$ plastic syringe without a cannula to children in a knee to chest position. The children were observed for one hour after drug administration and received a further half dose if the drug was expelled during this period. ${ }^{8}$ Children presenting with bloody stools were withdrawn from further rectal quinine and were given intramuscular quinine as rescue treatment. The drug was administered (maximum of six times) under medical supervision every 12 hours until the patient was able to swallow tablets. Quinine was then given orally ( $8 \mathrm{mg} / \mathrm{kg}$, every eight hours) to complete a seven day course.

\section{Laboratory tests}

We prepared Giemsa stained thick and thin films from blood obtained from the children by finger prick at enrolment and on days $3,5,7$, and 14 . The microscopist was blinded to the patients' clinical state or treatment. A routine anoscopic examination was carried out before treatment and on days 3,5 , and 7 for the first 240 children in each group. Further examinations were systematically carried out if blood was reported in stools. Children with abnormalities on anoscopy were followed by a gastroenterologist until they were cured. Parasitological examinations and bacteriological culture were carried out on mucoid, bloody, or diarrhoeal stools.

\section{Outcome measures}

The primary safety outcome was the presence of blood in stools and the secondary safety outcome was the onset of diarrhoea (more than three stools per day).

We used early treatment failure as the primary efficacy outcome, and the five secondary efficacy outcomes of late clini- cal failure and late parasitological failure according to standard World Health Organization guidelines, ${ }^{12}$ frequencies of deterioration to severe malaria, fever clearance and time to starting oral intake. The fever clearance time was defined as the time from the start of treatment to the first of two temperature readings below $37.5^{\circ} \mathrm{C}$.

\section{Sample size}

The sample size was calculated for the primary safety outcome, which suggested 449 patients in each group (for $80 \%$ power and $5 \%$ significance level). This was assuming that $3.5 \%$ and $0.6 \%$ of patients had blood in their stools after rectal and intramuscular quinine, respectively, based on a preliminary study in Niger ${ }^{13}$ and taking into account the high use of a traditional enema in the study region. This sample size allowed detection of a difference of $3.2 \%$ in early treatment failures assuming $1 \%$ in the intramuscular group. We calculated that we would need to carry out anoscopic examinations on 220 children in each group, assuming $0.5 \%$ and $5.5 \%$ of lesions after intramuscular and rectal administrations, respectively. We added $10 \%$ more children to allow for loss to follow up.

\section{Statistical analysis}

An independent statistician analysed the data on an intention to treat basis using Epilnfo 6.01 and SAS 8.1 programs. $\chi^{2}$ and Fisher's exact tests were used for categorical variables, Student's $t$ test and analysis of variance (F test) for normally distributed continuous data, and Bartlett's test to verify the homogeneity of variances. If necessary, non-parametric Mann-Whitney and Kruskal Wallis's tests were used. The groups were compared using absolute differences, with 95\% confidence intervals.

\section{Results}

A total of 898 children and young people fulfilled the inclusion criteria and were randomly assigned to either rectal quinine or intramuscular quinine (fig 1). The treatment groups were

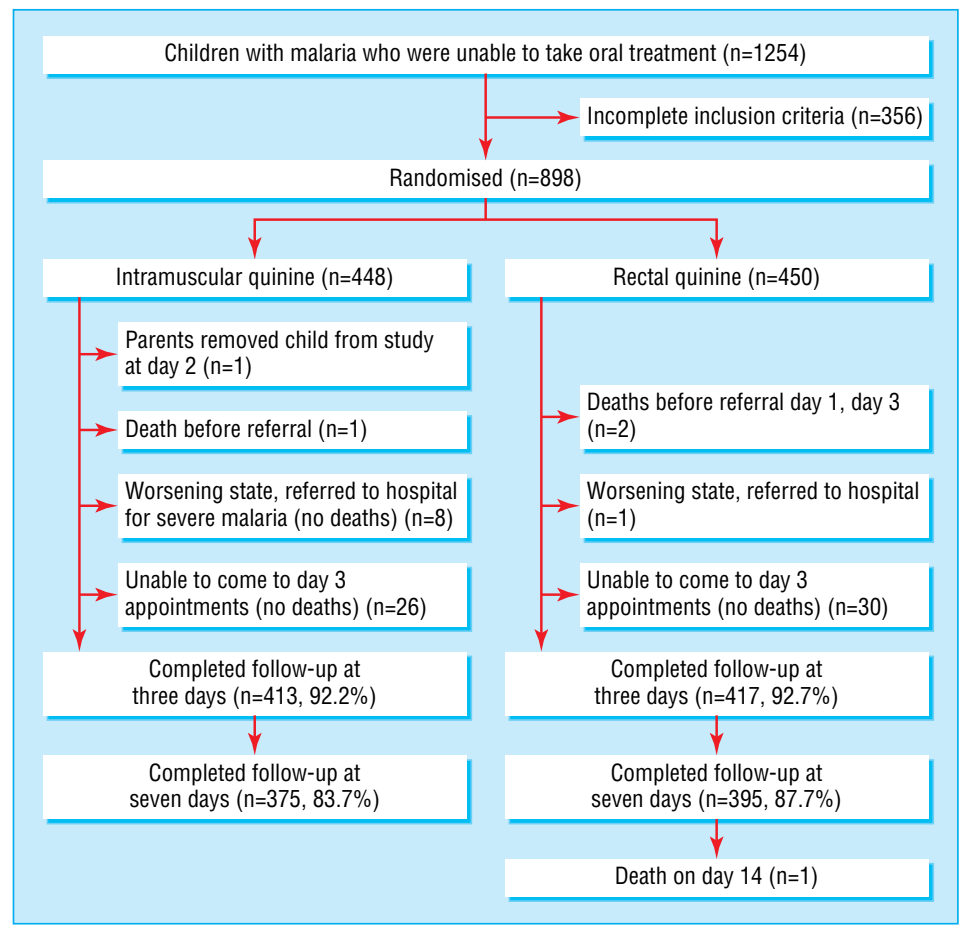

Fig 1 Flow of participants through trial 
comparable at baseline (table 1). The dropout rate was higher in the intramuscular quinine group after day 3 .

\section{Safety}

Table 2 shows the main side effects observed in the two treatment groups. Blood in stools was rare but was more common in the rectal group and resolved after withdrawal of rectal quinine (in 19 children by day 5 and in two children by day 14). Blood in stools was associated with anoscopic lesions in nine of 21 patients $(43 \%)$. Few parasitological or bacteriological infestations potentially responsible for the presence of the blood were observed. Expulsion of mucoid stools - the most common side effect-correlated with painful anal contraction but not with bloody stools, diarrhoea, or abnormalities on anoscopy. Mucoid stools decreased rapidly with change to the oral route (fig 2). Early rectal expulsion of quinine occurred in $40(8.8 \%)$ children, with no subsequent expulsion after administration of half dose quinine.

Anoscopic examination was carried out in 248 (55\%) children given intramuscular quinine and in 259 (57\%) given rectal quinine. Non-specific hyperaemia of the rectal mucosa was observed in both the intramuscular $(n=1)$ and rectal $(n=3)$ groups. Noticeable inflammation of the mucosa was observed in nine children in the rectal group. Six children with mild inflammations or single microulcerations recovered within two days and two children with moderate multiple microulcerations recovered within four and 11 days. One child who had severe ulceration of the rectum, normal results after an anal sphincter examination, and a cutaneous perianal abscess that required surgical treatment, recovered within one month. The initial lesion may have been aggravated by unhygienic scratching.

Intramuscular injection was painful and caused local inflammation and a high rate of transitory impaired mobility $(\mathrm{n}=68$, $15 \%)$. Inflammation at the injection site occurred rapidly (211/443, 47\% and 95/44, 21\% after the first and second injection), persisted (24\%, 92/375 on day 7 ), and was associated with a higher fever recurrence rate (table 3 ).

\section{Efficacy}

Early treatment failure was higher in the rectal group than in the intramuscular group (table 3). All children had negative blood slide results at day 5 except two children in each group. These last children were aparasitaemic on days 7 and 14. Fever recurrence was higher with intramuscular quinine than with rectal quinine and related to inflammation of the gluteus. Other secondary efficacy outcomes (late clinical failure, late parasitological failure, fever clearance time, time to starting oral intake

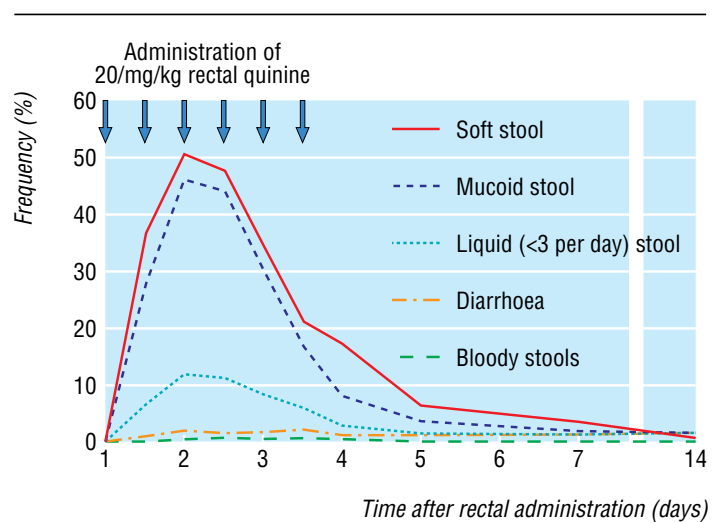

Fig 2 Evolution of stools after multiple rectal administrations to 450 children with Plasmodium falciparum malaria
Table 1 Clinical and laboratory data of children at baseline. Values are numbers (percentages) unless stated otherwise

\begin{tabular}{|c|c|c|}
\hline Characteristic & Rectal group $(n=450)$ & Intramuscular group ( $n=448$ ) \\
\hline Mean (SD) age (years) & $4.8(3.3)$ & $5.4(3.8)$ \\
\hline Mean (SD) weight $(\mathrm{kg})$ & $16.3(8.0)$ & $18.3(11.0)$ \\
\hline $\begin{array}{l}\text { Mean (SD) days of illness before } \\
\text { study }\end{array}$ & $3.4(3.1)$ & $3.3(4.1)$ \\
\hline Previous traditional enema* & $100(22)$ & $105(23)$ \\
\hline Previous anal disease: & $58(13)$ & $54(12)$ \\
\hline Anusitis & $8(1.7)$ & $8(1.7)$ \\
\hline Fissure & $52(11.5)$ & $42(9.3)$ \\
\hline Prolapse & $1(0.2)$ & $1(0.2)$ \\
\hline Previous antimalarial treatment: & $203(45)$ & $187(41)$ \\
\hline Chloroquine & $174(38.6)$ & $163(36.3)$ \\
\hline Quinine & $20(4.4)$ & $18(4.0)$ \\
\hline Amodiaquine & $9(2.0)$ & $6(1.3)$ \\
\hline Vomiting & $406(90)$ & $386(86)$ \\
\hline Seizures & $4(1)$ & $7(1)$ \\
\hline General weakness & $40(9)$ & $55(12)$ \\
\hline Associated disease $\dagger$ & $45(10)$ & $52(12)$ \\
\hline Mean (SD) temperature $\left({ }^{\circ} \mathrm{C}\right)$ & $38.8(1)$ & $38.9(1)$ \\
\hline $\begin{array}{l}\text { Geometric mean of parasitaemia } \\
\text { per } \mu \text { l of blood (range Min-Max) }\end{array}$ & $\begin{array}{c}11720 \text { (1767 to } 77 \\
740)\end{array}$ & 12382 (1686 to 90938 ) \\
\hline
\end{tabular}

*56 children in each group reported use of suppositories, none reported rectal practice in preceding week.

†94\% attributable to respiratory tract infection.

and rate of deterioration to severe malaria) did not reach statistical significance between the groups (table 3). Clinical deterioration and mortality were similar between the intramuscular and rectal groups $(9 / 448 v 4 / 450)$.

Table 2 Safety outcomes observed in children with malaria after administration of intramuscular or rectal quinine

\begin{tabular}{|c|c|c|c|c|}
\hline Outcomes & $\begin{array}{l}\text { Rectal group } \\
(\mathrm{n}=450)\end{array}$ & $\%(95 \% \mathrm{Cl})$ & $\begin{array}{l}\text { Intramuscular } \\
\text { group }(n=448)\end{array}$ & $\%(95 \% \mathrm{CI})$ \\
\hline \multicolumn{5}{|l|}{ Rectal side effects: } \\
\hline $\begin{array}{l}\text { Presence of blood in } \\
\text { stools* }\end{array}$ & 21 & $5(3$ to 7$)$ & 3 & 1 (0 to 1$)$ \\
\hline Blood in stools & 4 & 1 (0 to 2) & 0 & 0 \\
\hline Blood striation $†$ & 17 & 4 (2 to 5) & 3 & 1 (0 to 1$)$ \\
\hline $\begin{array}{l}\text { At least one abnormal } \\
\text { stoolf }\end{array}$ & 357 & 79 (76 to 83) & 50 & 11 (8 to 14) \\
\hline Soft stools & 105 & 23 (19 to 27) & 24 & 5 (3 to 7$)$ \\
\hline $\begin{array}{l}\text { Liquid stools }(<3 \text { per } \\
\text { day) }\end{array}$ & 105 & 23 (19 to 27 ) & 23 & 5 (3 to 7 ) \\
\hline $\begin{array}{l}\text { Diarrhoea ( } \geq 3 \text { stools per } \\
\text { day)§ }\end{array}$ & 21 & 5 (3 to 6$)$ & 5 & 1 (0 to 2$)$ \\
\hline Mucoid stools & 296 & 66 (61 to 70) & 22 & $5(3$ to 7$)$ \\
\hline $\begin{array}{l}\text { Painful anal sphincter } \\
\text { contraction and tenesmus }\end{array}$ & 46 & 10 (7 to 13$)$ & 2 & $0.4(0$ to 1$)$ \\
\hline $\begin{array}{l}\text { Isolated painful anal } \\
\text { sphincter contraction }\end{array}$ & 19 & 4 (2 to 6$)$ & 1 & $0.2(0$ to 1$)$ \\
\hline Isolated tenesmus & 10 & 2 (1 to 4) & 1 & $0.2(0$ to 1$)$ \\
\hline Anal pruritus & 2 & 0.4 (0 to 1$)$ & 1 & $0.2(0$ to 1$)$ \\
\hline \multicolumn{5}{|l|}{ Intramuscular side effects: } \\
\hline $\begin{array}{l}\text { Local inflammation of } \\
\text { gluteus muscle }\end{array}$ & 0 & & 355 & $\begin{array}{c}79 \\
\text { (75 to 83) }\end{array}$ \\
\hline Impaired mobility & 0 & & 68 & $\begin{array}{c}15 \\
(12 \text { to } 18)\end{array}$ \\
\hline Decreased hip mobility & 0 & & 9 & $2(0$ to 3$)$ \\
\hline Leg paraesthesia & 0 & & 1 & $0.2(0$ to 1$)$ \\
\hline $\begin{array}{l}\text { Pain during or after } \\
\text { administrationף }\end{array}$ & 9 & 2 (0 to 3) & 404 & $\begin{array}{c}90 \\
\text { (87 to 92) }\end{array}$ \\
\hline Abscess & 1 & 0.2 (0 to 1$)$ & 2 & $0.4(0$ to 1$)$ \\
\hline
\end{tabular}

${ }^{*}$ Absolute difference $3.9 \%$ (95\% confidence interval $2 \%$ to $6 \%$ ), $P<0.001$.

tAbsolute difference $3.1 \%$ ( $1 \%$ to $5 \%), P=0.001$.

Aabsolute difference $68.1 \%(62 \%$ to $75 \%), P<0.001$

§Absolute difference $3.5 \%$ ( $1 \%$ to $6 \%$ ), $P=0.001$.

IIntramuscular $v$ rectal: absolute difference $88.1 \%$ ( $85 \%$ to $91 \%), P<0.001$. 


\section{Discussion}

Quinine administered by the rectal route has an acceptable safety profile in the early management of moderately severe malaria in children who are unable to take oral treatment. Efficacy was lower, although still acceptable, than with intramuscular quinine at three days but achieved rates similar to intramuscular quinine from day 5 onwards.

The main limitation of our trial is the unblinded design; the use of sham injections or sham rectal administrations was not possible for ethical reasons. We minimised this potential bias by ensuring blinding for treatment allocation and slide reading.

\section{Safety}

The rectal route was painless. Its main drawback, mucoid stools, was not associated with diarrhoea and probably resulted from over-stimulation of the rectal mucosa. Primary caregivers and health assistants should be informed of this common but minor and temporary side effect.

Blood in stools and lesions detected on anoscopy were higher than expected from previous observations in Niger where enemas are infrequent, ${ }^{13}$ and required discontinuation of rectal treatment. As previously observed in the west of Burkina Faso, ${ }^{14}$ nearly $25 \%$ of children receive regular traditional enemas containing a wide variety of products such as caustic plants or medicines. The past use of traditional enemas was highly correlated with a history of anal symptoms (see table 1) and may sensitise the rectal mucosa to the irritant effect of the solution. We would expect the frequency of blood in children's stools to be lower in most of Africa, where enemas are not routinely used. We observed one severe lesion, with complete recovery. No lesions have been reported in Madagascar where rectal quinine was first developed in $1985-8^{15}$ or during clinical studies in Niger, Togo, Congo, and Senegal. ${ }^{16-18}$ In Niger, rectal quinine was officially adopted in 1994. One case of severe anal abscess with complete recovery and one severe complication from intramuscular injection were reported. ${ }^{19}$

The main disadvantage of rectal administration was expulsion. Early expulsion during the first hour after administration of quinine decreases blood concentrations of quinine by $50 \%$, but immediate administration of half a dose restores an effective blood concentration-time profile. ${ }^{8}$ Compression of the buttocks for five minutes can reduce expulsion. Rectal quinine formulations with better tolerability and high bioavailability are being evaluated for children. ${ }^{50}$ Manufacturing cost and availability are still of concern.

Table 3 Therapeutic responses to intramuscular and rectal administration of quinine in children with malaria. Values are means $(95 \%$ confidence intervals) unless stated otherwise

\begin{tabular}{|c|c|c|}
\hline Variable & Rectal group $(n=450)$ & $\begin{array}{c}\text { Intramuscular group } \\
(\mathrm{n}=448)\end{array}$ \\
\hline Quinine doses (mg/kg) & 20.0 (18.1 to 22.0$)$ & 12.8 (11.2 to 14.3$)$ \\
\hline $\begin{array}{l}\text { No of quinine administrations } \\
\text { before switching to oral route }\end{array}$ & 3.4 (2.1 to 4.8$)$ & 3.6 (2.3 to 5.0$)$ \\
\hline $\begin{array}{l}\text { No (\%) with early treatment failure } \\
\text { on day } 3^{*}\end{array}$ & $26 / 417$ (6) & $13 / 413(3)$ \\
\hline Late clinical failure & 1 & 0 \\
\hline Late parasitological failure & 0 & 0 \\
\hline Fever clearance time (days) & 1.8 (0.5 to 3.1$)$ & 1.7 (0.3 to 3.1$)$ \\
\hline Time to oral intake (days) & $1.3(0.2$ to 2.3$)$ & 1.3 (0.5 to 2.0$)$ \\
\hline $\begin{array}{l}\text { No }(\%) \text { with fever recurrence on } \\
\text { day } 7 \dagger\end{array}$ & 18/395 (5) & $37 / 375(10)$ \\
\hline
\end{tabular}

\section{What is already known on this topic}

Intramuscular quinine is the treatment of choice for severe Plasmodium falciparum malaria in the field

High mortality in children with severe malaria is related to a lack of early treatment of potentially evolving cases

Intramuscular injections of quinine are painful, may transmit infectious diseases, and may lead to impaired mobility

\section{What this study adds}

Rectal quinine has an acceptable safety profile

Rectal quinine could be used to treat moderately severe malaria in the field when qualified staff and equipment are not available

Pain $(90 \%)$ and inflammation (79\%) of the injection site were the main side effects of intramuscular quinine. Fear of injections can impair compliance with treatment and may explain the higher dropout rate in this group. Fever associated with developing abscesses after intramuscular quinine may lead to a mistaken diagnosis of late treatment failure. Limb paralysis associated with intramuscular quinine is rare but has devastating consequences. In field conditions, transmission of bloodborne pathogens through intramuscular injection is high ${ }^{2}$ but was not evaluated in our study.

\section{Efficacy}

In both treatment groups the frequency of clinical deterioration to severe malaria was similar, although the rectal group had a higher frequency of early treatment failures. Similar drug absorption has been reported after $20 \mathrm{mg} / \mathrm{kg}$ rectal quinine and $12 \mathrm{mg} / \mathrm{kg}$ intramuscular quinine. ${ }^{8}$ Operational constraints and field conditions limited the follow-up to 14 days and therefore we may have under-estimated late clinical parasitaemia and late clinical failure in both groups. Families were, however, encouraged to come back after 14 days if any problems occurred, and some did. Differences observed between rectal and intramuscular groups were moderate; deterioration to severe malaria was prevented in 446 of $450(99 \%)$ patients given rectal quinine compared with 439 of 448 (98\%) patients given intramuscular quinine $(\mathrm{P}=0.2)$.

The inability to take oral treatment represents the first step towards severe malaria in children, which can occur rapidly. ${ }^{1}$ Effective management requires the ability to initiate prompt treatment with a potent antimalarial drug. The availability of safe and effective drug administration is a major limiting factor in field conditions.

Quinine vials are available in many remote areas of Africa, but injectable disposables are harder to find. Rectal treatment may be initiated early within the community. ${ }^{18}$ The rectal administration of a quinine solution formulated for parenteral injection represents a pragmatic approach allowing availability and immediate treatment anywhere.

Rectal artemisinin derivatives are promising, with virtually no adverse effects. ${ }^{21-23}$ Nevertheless, artemisinin suppositories are not available at the field level, and the high recrudescence of parasitaemia requires combination therapy. ${ }^{24}$ Rectal quinine could fill the gap for the early management of moderately severe malaria in children. 
We thank the staff of Hamdallaye Health Centre, the Centre Muraz Epidemiological Unit, and the Malaria Unit (RT Guiguemde), the National Hospital Sanou Souro Medecine, Surgery and Pediatric (B Nacro) ward in Burkina Faso, the Bicêtre Hospital Pharmacological Unit (France), and the statistical staff of MRC (France); RT Guiguemde and M Sawadogo for helpful advice; A Sawadogo and F Rasoananadrasana for examination for parasites; I Achan, P Newton, L Srour, and M Strobel for revising the document. We also thank the French Ministry of Foreign Affairs for technical assistance.

Contributors: $\mathrm{HB}$ was responsible for the overall coordination of the study and contributed to the study design, enrolment, examination of the children, field supervision and data analysis; $\mathrm{He}$ will act as guarantor for the paper. TBK enrolled and followed the children, collected and analysed the data. NN contributed to the design of the study and the interpretation of the data. JCC contributed to the analysis of the data. EP contributed to the analysis and interpretation of the data. All authors contributed to the writing of the paper.

Funding: Impact Malaria, Sanofi-Synthelabo (Gentilly France).

Competing interests: None declared.

Ethical approval: Centre Muraz ethical committee and Ministry of Health of Burkina Faso.

1 World Health Organization. Severe falciparum malaria. Trans $R$ Soc Trop Med Hyg 2000:94(suppl 1)(3rd ed):1-90.

2 Simonsen L, Kane A, Lloyd J, Zaffran M, Kane M. Unsafe injections in the developing world and transmission of bloodborne pathogens: a review. Bull WHO 1999;77:789800.

3 Van Hoogdalem EJ, De Boer AG, Breimer DD. Pharmacokinetics of rectal drug administration. Part I. General considerations and clinical applications of centrally acting drugs. Clin Pharmacokinet 1991;21:11-26.

4 Barennes H, Kahiatani F, Pussard E, Clavier F, Meynard D, Njifountawouo S, et al. Intrarectal Quinimax for the treatment of Plasmodium falciparum malaria in children in Niger: efficacy and pharmacokinetics. Trans R Soc Trop Med Hyg 1995;89:418-21.

5 Barennes H, Pussard E, Mahaman SA, Clavier F, Kahiatani F, Granic G, et al. Efficacy and pharmacokinetics of a new intrarectal quinine formulation in children with Plasmodium falciparum malaria. Br J Clin Pharmacol 1996;41:389-95.

6 Barennes H, Munjakazi JM, Verdier F, Clavier F, Pussard E. An open randomized cliniBarennes H, Munjakazi JM, Verdier F, Clavier F, Pussard E. An open randomized clini-
cal study of intrarectal versus infused Quinimax for the treatment of childhood cal study of intrarectal versus infused Quinimax for the treatm
cerebral malaria in Niger. Trans R Soc Trop Med Hyg 1998;92:437-40.

7 Barennes H, Daouda K, Pussard E, Munjakazi JM, Fernan M, Sherouat H, et al. Administration intrarectale de la quinine: un traitement précoce du paludisme grave de l'enfant? Cahiers Santé 2001;11:145-53.

8 Pussard E, Straczek C, Kaboré I, Bicaba B, Balima-Koussoubé T, Bourrée P, et al. Dosedependent resorption of quinine after intrarectal administration to children with moderate falciparum malaria. Antimicrob Agents Chemother 2004:48(11):4422-6.

9 Del Nero L, Lamizana L, Nebie I, Sare S, Bougouma L, Pietra V. In vivo sensitivity of Plasmodium falciparum to halofantrine hydrochloride in Burkina Faso. Am J Trop Med Hyg 1994;50:102-6.

10 Diallo AH, Guiguemde T, Ki-Zerbo G. Clinical and parasitological aspects of severe malaria in adults in an urban area of Bobo-Dioulasso (Burkina Faso). Bull Soc Pathol Exot 2003:99-100.
11 Barennes H, Sterlingot H, Nagot N, Meda HA, Kaboré M, Sanou M, et al. Intrarectal pharmacokinetics of two formulations of quinine in children with falciparum malaria. Eur J Clin Pharmacol 2003;58:649-59.

12 World Health Organization. Monitoring antimalarial drug resistance. Report of a WHO consultation. Geneva: WHO, 2001

13 Barennes H, Mahaman S, Munjakazi JM, Khenine A. Tolérance de la quinine en solution intrarectale chez l'enfant Africain. Med Trop 1999;59:383-7.

14 Huygens $\mathrm{P}$, Konaté B, Traoré A, Barennes H. Hygiène et socialisation du nourisson: le lavement rectal en milieu urbain à Bobo Dioulasso. Cahiers Santé 2002;12:357-62.

15 Barennes $\mathrm{H}$. Is intrarectal quinine a safe alternative to intramuscular injectable quinine? Trop Doct 1994;24:32-3.

16 Boureima SH, Idrissa M. Evolution de la densité parasitaire chez les enfants paludéens après traitement à la quinine injectable diluée et administrée en intrarectale. Malaria 1996:8:25-30.

17 Assimadi JK, Gbadoe AD, Agbodjan-Djossou O, Larsen SE, Kusiaku K, Lawson-Evi K, et al. Quinine injectable diluée en intramusculaire et en intrarectal: efficacité et tolérance comparées dans le paludisme de l'enfant. Med Trop 2002;62:158-62.

18 Le Hesran JY, Ndiaye JL, Verdier F, Daff B, Gaye O, Trust W. Intrarectal quinine, an alternative to parenteral injections for treatment of childhood malaria in rural health centre. Durban: Multilateral initiative on malaria African malaria conference, 1999. C-86.

19 Harouna Y, Gamatié Y, Gamatié S, Mounkaila H, Boureima M. A propos de deux complications chirurgicales graves de l'usage de la quinine intra-musculaire et intrarectale. Bull Soc Pathol Exot 2000;93:328-30.

20 Fawaz F, Koffi A, Guyot M, Millet P. Comparative in vitro-in vivo study of two quinine rectal gel formulations. Int J Pharm 2004; 280:151-62.

21 AcengJR, Byarugaba JS, Tumwine JK. Rectal artemether versus intravenous quinine for the treatment of cerebral malaria children in Uganda: randomised clinical trial. $B M$ J 2005;330:334-8

22 Dondorp A, Nosten F, Stepniewska K, Day N, White N; South East Asian Quinine Artesunate Malaria Trial Group (SEAQUAMAT). Artesunate versus quinine for treatment of severe falciparum malaria: a randomised trial. Lancet 2005;366:717-25.

23 Barnes KI, Mwenechanya J, Tembo M, Mcllleron H, Folb PI, Ribeiro I, et al. Efficacy of rectal artesunate compared with parenteral quinine in initial treatment of moderately severe malaria in African children and adults: a randomised study. Lance 2004;15:1598-605.

24 Adjulk M, Aonamey P, Babiker A, Borrmann S, Brasseur P, Cisse M, et al Amodiaquine-artesunate versus amodiaquine for uncomplicated Plasmodium falciparum malaria in African children: a randomised multicentre trial. Lancet 2002:359:1365-72

(Accepted 23 February 2006)

bmj.com 2006;332:1055

Centre MURAZ, 01BP390 Bobo-Dioulasso, Burkina Faso

Hubert Barennes epidemiologist

Tatiana Balima-Koussoubé general practitioner

Nicolas Nagot epidemiologist

Methodology and Research Centre, Cernay les Reims, France

Jean-Christophe Charpentier statistician

Hôpital du Kremlin Bicêtre, Service de Pharmacologie, France Eric Pussard pharmacologist

Correspondence to: $\mathrm{H}$ Barennes, Institut de la francophonie pour la médicine tropicale, BP 9519 Vientiane, Lao People's Democratic Republic hubert.barennes@auf.org 